\title{
RESULTS OF REVASCULARIZATION IN PATIENTS WITH SEVERE LEFT VENTRICULAR DYSFUNCTION
}

Lynda L. Mickleborough, MD

Susan Carson, AHT,

Miguel Tamariz, BSc

Joan Ivanov, MSc objective: In patients with coronary disease and poor left ventricular function, bypass grafting remains a surgical challenge. This study evaluates experience in 125 consecutive patients with ejection fraction less than $20 \%$ (study group). Methods: Preoperative viability studies were not used for patient selection. Clinical data were prospectively collected. The average age of the study subjects was $59 \pm 9$ years, and $112(90 \%)$ were male. Most patients (108 [86\%]) were in symptom class III or IV. Main indications for surgery included angina in $62(50 \%)$, heart failure and angina in $36(29 \%)$, heart failure in $9(7 \%)$, ventricular arrhythmia in $2(2 \%)$, and critical anatomy in $16(13 \%)$. Significant mitral regurgitation was present in $48(38 \%)$, and distal vessels were poorly visualized in $67(54 \%)$. At surgery, temperature mapping guided an integrated approach to cold cardioplegia. Results in this group were compared with those obtained in case-matched control subjects receiving cardioplegia without temperature mapping (matched for age, sex, functional class, and urgency of operation). Results: Hospital morbidity (intra-aortic balloon pump support) and mortality rates were significantly lower in the study group versus those of control subjects $(15 \%$ vs $30 \%, P=$ .004 ; and $4 \%$ vs $11 \%, P=.03$, respectively). In study patients the 5-year actuarial survival was $72 \%$. Among survivors, both anginal class and heart failure class improved significantly. By means of multivariate analysis, survival was adversely affected by older age, class IV symptoms, and poorly visualized distal vessels. Conclusions: These results support the use of coronary artery bypass grafting in patients with severe left ventricular dysfunction without case selection on the basis of viability studies or visibility of distal vessels. Low hospital morbidity and mortality rates have been achieved when temperature mapping guides cardioplegia. Symptoms are improved in most patients, and long-term survival is encouraging. ( $J$ Thorac Cardiovasc Surg 2000;119:550-7)
$P^{2}$ tients with coronary disease and advanced left ventricular (LV) dysfunction (ejection fraction [EF] $<20 \%$ ) have a poor prognosis. When treated medically, they have limited survival ${ }^{1-5}$ and usually die of cardiac causes. Transplantation is an effective treatment option but is limited by availability of donor organs. Therefore

From the University of Toronto, Toronto, Ontario, Canada.

Received for publication Feb 23, 1999; revisions requested Mar 19, 1999; revisions received Sept 14, 1999; accepted for publication Oct 5, 1999.

Address for reprints: Lynda L. Mickleborough, MD, EN 13-217, The Toronto Hospital, 200 Elizabeth St, Toronto, Ontario M5G 2C4, Canada (E-mail: lmickleborough@ @orhosp.toronto.on.ca).

Copyright $\odot 2000$ by Mosby, Inc.

$0022-5223 / 2000 \$ 12.00+0 \quad \mathbf{1 2 / 1 / 1 0 3 4 6 7}$

doi: $10.1067 / \mathrm{mtc} .2000 .103467$ in these patients revascularization should always be considered as a treatment option.

In the past, revascularization in such patients was associated with increased operative mortality rates. ${ }^{6}$ Recent studies ${ }^{7-9}$ report lower mortality rates but often use selection criteria to exclude high-risk patients or those "least likely to benefit from revascularization." It has been suggested that symptoms of angina versus symptoms of heart failure are associated with a favorable outcome. ${ }^{10}$ Others recommend demonstration of reversible ischemia or viability of hibernating myocardium by positron emission tomographic scanning or dobutamine echocardiography to select patients for this approach. ${ }^{11-13}$ In other centers revascularization in patients with poor LV function has been recommended only when distal vessels are eminently graftable. ${ }^{14}$ 
We have taken a more liberal approach to revascularization in patients with poor EF $(<20 \%)$. We have not excluded patients because of lack of significant angina or uncertainty about completeness of revascularization, nor have we used viability studies to select candidates for grafting. In patients with poor LV function and an akinetic or dyskinetic area, we used intraoperative assessment of regional wall thickness and contractility to determine whether the area in question is viable and should be revascularized or whether it has undergone enough scarring and thinning to warrant resection (partial ventriculectomy) and operative remodeling. ${ }^{15}$ Patients undergoing wall excision were excluded from this series. Patients with EFs of less than $20 \%$ were considered unsuitable for surgery if they had angiographic evidence of diffuse distal disease in all vessels, severe mitral regurgitation, or comorbidities that significantly increased operative risk.

In patients with little functional reserve, we believe favorable results can be achieved only with optimal myocardial protection. We have assessed delivery of cold cardioplegic solution by temperature mapping and used an integrated approach (antegrade \pm retrograde \pm infusion through grafts) to obtain uniform cooling.

The present study was undertaken to review the results achieved by using this approach. We review indications for operation, operative morbidity and mortality rates, improvement in symptom status, and late survival in our series (study group). To assess the effect of cardioplegic technique on early results, we have compared study patients with a group of case-matched control subjects in whom myocardial protection was not guided by temperature mapping.

\section{Methods}

Between January 1982 and September 1997, 2359 patients underwent isolated coronary artery bypass grafting by one author (L. M.) at The Toronto Hospital. Of these, 125 consecutive patients with EFs of less than $20 \%$, as determined by cineangiography, comprised the study group. Data were prospectively collected by trained chart reviewers by using a standard data collection form. A less-detailed data set acquired prospectively on all patients operated on at The Toronto Hospital was used to obtain our control group. From this large pool (470 patients), the single patient with the best match for EF $(<20 \%)$, year of operation, age, sex, symptom class, and urgency was chosen for the control group. Because of concern about the fairness of comparison between the study and control groups, we attempted to develop a propensity score for membership in the study group versus the control group by using multivariable logistic regression. Variables analyzed included age, sex, symptom class, acute coronary insufficiency, recent myocardial infarction, surgical priority, extent of coronary artery disease, presence or absence of left main stenosis, diabetes, hypertension, and peripheral vascular disease. The only variable found to be an independent predictor of group membership was left main coronary artery disease, which was more prevalent in the control group. The direction of results in each of these subgroups was the same as that seen in the overall matched case analysis.

Preoperative clinical variables are given in Table I. Timing of operation was designated as elective on the same admission, urgent (within 72 hours of an event), or emergency (from cardiac care unit or catheterization laboratory with an acutely unstable patient). Information with regard to primary indication for an operation or ventricular arrhythmia was available only for the study group.

Catheterization data. Catheterization data are shown in Table II. Cardiac catheterization was performed in all patients to assess ventricular function and extent of coronary disease. Coronary narrowing of $50 \%$ or greater was considered significant. The number of diseased vessels, EF, and, in the study group, the number of vessels with poor visualization (questionably graftable) were recorded.

Operative technique. Fentanyl citrate was used for induction and maintenance of anesthesia. Between 1982 and 1989, moderate systemic hypothermia $\left(25^{\circ} \mathrm{C}\right)$ was used. Since 1989 , body temperature has been allowed to drift, and no active cooling has been used (mild hypothermia). Cardioplegic techniques have evolved over time. Cold crystalloid solution switched to cold blood in 1983, and a terminal hot shot was added in 1985 .

In the study group after initial delivery of $1 \mathrm{~L}$ of cold cardioplegic solution, myocardial temperature in three major distributions was measured. In cases of unsatisfactory cooling (regional temperature $>18^{\circ} \mathrm{C}$ ), a graft was constructed to the warm area first (diagonal in the case of disease of the left anterior descending coronary artery with planned use of the left internal thoracic artery [LITA]) and additional cardioplegic solution was given down the completed graft to achieve uniform cooling. Since 1993, in cases of inadequate cooling, retrograde cardioplegia has been used.

In the control group (Table III) a variety of cardioplegic techniques have been used (cold, warm or tepid, antegrade, retrograde, and down completed grafts), but temperature mapping was not used to ensure uniform delivery.

Information obtained from operative records included technique of myocardial protection, number of grafts, use of LITA, pump time, crossclamp time, and, in study cases, information about the size and quality of distal vessels (Table III).

Postoperative care and outcome. Operative mortality (death within 30 days or during hospital stay) and morbidity rates were reviewed. Definitions for perioperative myocardial infarction, low-output syndrome, and perioperative stroke have been previously reported. ${ }^{16}$ For study cases, follow-up was performed in 1998 by telephone interview with the patient or referring physician and office visits when clinically indicated.

Statistical analysis. The SAS (SAS Institute, Cary, NC) 
Table I. Preoperative clinical variables

\begin{tabular}{|c|c|c|c|}
\hline & Study group & $\begin{array}{l}\text { Control } \\
\text { subjects }\end{array}$ & $\mathrm{P}$ value \\
\hline Age (y) & $60 \pm 10$ & $60 \pm 10$ & $>.2$ \\
\hline $\operatorname{Sex}(M / F)$ & $112 / 13$ & $112 / 13$ & $>.2$ \\
\hline \multicolumn{4}{|l|}{ Overall symptom class } \\
\hline I & $3 / 125(2 \%)$ & $2 / 125(2 \%)$ & $>.2$ \\
\hline II & $14 / 125(11 \%)$ & $13 / 125(10 \%)$ & \\
\hline III & $39 / 125(31 \%)$ & $42 / 125(34 \%)$ & \\
\hline IV & $69 / 125(55 \%)$ & $68 / 125(54 \%)$ & \\
\hline $\mathrm{CHF}^{*}$ & $31 / 97(32 \%)$ & $21 / 97(22 \%)$ & .11 \\
\hline \multicolumn{4}{|l|}{ Severity of angina } \\
\hline 0 - none & 0 & 0 & $>.2$ \\
\hline I - stable & $47 / 125(38 \%)$ & $46 / 125(37 \%)$ & \\
\hline II - crescendo & $49 / 125(39 \%)$ & $46 / 125(37 \%)$ & \\
\hline $\begin{array}{l}\text { III - acute coronary } \\
\text { insufficiency }\end{array}$ & $29 / 125(23 \%)$ & $33 / 125(26 \%)$ & \\
\hline \multicolumn{4}{|l|}{ Timing } \\
\hline Elective & $79 / 125(63 \%)$ & $83 / 125(66 \%)$ & $>.2$ \\
\hline Same hospitalization & $16 / 125(13 \%)$ & $22 / 125(18 \%)$ & \\
\hline Urgent & $26 / 125(21 \%)$ & $16 / 125(13 \%)$ & \\
\hline Emergency & $4 / 125(3 \%)$ & $4 / 125(3 \%)$ & \\
\hline Diabetes & $24 / 83(29 \%)$ & $21 / 81(26 \%)$ & $>.2$ \\
\hline Hypertension & $57 / 97(59 \%)$ & $30 / 69(44 \%)$ & .05 \\
\hline PVD & $19 / 97(20 \%)$ & $16 / 85(19 \%)$ & $>.2$ \\
\hline Preoperative IABP & $7 / 125(6 \%)$ & $5 / 125(4 \%)$ & $>.2$ \\
\hline \multicolumn{4}{|l|}{$\begin{array}{l}\text { Preoperative ventricular } \\
\text { arrhythmia }\end{array}$} \\
\hline PVCs & $8 / 125(6 \%)$ & & \\
\hline $\mathrm{VT} / \mathrm{VF}$ & $31 / 125(25 \%)$ & & \\
\hline \multicolumn{4}{|l|}{$\begin{array}{l}\text { Primary indication for } \\
\text { operation }\end{array}$} \\
\hline Heart failure & $9 / 125(7 \%)$ & & \\
\hline Angina & $62 / 125(50 \%)$ & & \\
\hline Both & $36 / 125(29 \%)$ & & \\
\hline Ventricular arrhythmia & $2 / 125(2 \%)$ & & \\
\hline Critical anatomy & $16 / 125(13 \%)$ & & \\
\hline
\end{tabular}

$P V D$, Peripheral vascular disease; $I A B P$, intra-aortic balloon pump; $P V C$, premature ventricular contraction.

*Information unavailable from divisional database before 1990.

Table II. Catheterization data

\begin{tabular}{lccc}
\hline & Study group & $\begin{array}{c}\text { Control } \\
\text { subjects }\end{array}$ & P value \\
\hline Diseased vessels & & & \\
1 & $2 / 125(2 \%)$ & $4 / 125(3 \%)$ & $>.2$ \\
2 & $24 / 125(18 \%)$ & $23 / 125(18 \%)$ & \\
3 & $100 / 125(80 \%)$ & $100 / 125(80 \%)$ & \\
Left main & $14 / 125(11 \%)$ & $17 / 125(14 \%)$ & \\
Possibly nongraftable & & & \\
$\quad$ vessels & & & \\
LAD & $25 / 125(20 \%)$ & & \\
Right & $41 / 125(33 \%)$ & & \\
Circumflex & $16 / 125(13 \%)$ & & \\
MR $\geq 2+$ & $48 / 125(38 \%)$ & & \\
Average EF $(\%)$ & $18 \pm 5$ & \\
\hline
\end{tabular}

$L A D$, Left anterior descending; $M R$, mitral regurgitation.
Table III. Intraoperative variables

\begin{tabular}{lccl}
\hline & Study group & $\begin{array}{c}\text { Control } \\
\text { subjects }\end{array}$ & P value \\
\hline Average No. of grafts & $3.7 \pm 0.7$ & $3.5 \pm 1.0$ & $>.2$ \\
Pump time (min) & $117.4 \pm 30.7$ & $85.7 \pm 23.2$ & .0001 \\
Crossclamp time (min) & $69.5 \pm 17.9$ & $59.7 \pm 18.7$ & .0004 \\
Use of LITA & $91 / 125(73 \%)$ & $70 / 125(56 \%)$ & .005 \\
Myocardial protection & & & \\
$\quad$ Mild hypothermia & $58 / 125(46 \%)$ & $62 / 125(50 \%)$ & \\
$\quad$ Moderate hypothermia & $67 / 125(54 \%)$ & $63 / 125(50 \%)$ & $>.2$ \\
Type of cardioplegia & & & \\
$\quad$ Cold crystalloid & $6 / 125(5 \%)$ & $5 / 125(4 \%)$ & \\
$\quad$ Cold blood & $119 / 125(95 \%)$ & $109 / 125(87 \%)$ & \\
$\quad$ Tepid blood & 0 & $7 / 125(6 \%)$ & \\
$\quad$ Warm blood & 0 & $4 / 125(3 \%)$ & .009 \\
Mode of delivery & & & \\
$\quad$ Antegrade & $112 / 125(90 \%)$ & $107 / 125(86 \%)$ & \\
Retrograde \pm antegrade & $13 / 125(10 \%)$ & $18 / 125(14 \%)$ & $>.2$ \\
\hline
\end{tabular}

and BMDP (BMDP Software, Los Angeles, Calif) programs were used for statistical analyses.

Patient characteristics and hospital outcomes were compared by using $t$ tests for continuous variables and the $\chi^{2}$ or Fisher exact test for categoric variables. Differences between preoperative and postoperative symptom status were compared by using linear trend analysis. Results are presented as means \pm $\mathrm{SD}$ in the text and tables and means \pm SEM in the figures.

The late survival was evaluated univariately by using Kaplan-Meier analyses and multivariately by using the Cox proportional hazards model with the following building strategy: variables with a univariate $P$ value of less than .25 or those of known biologic importance but failing to meet the critical $\alpha$-level were submitted for consideration to the multivariate analysis by means of stepwise selection. Variables considered for analysis in predicting long-term survival included age, sex, symptom class, presence or absence of congestive heart failure, severity of angina, urgency of surgery, recent myocardial infarction, diabetes, hypertension, peripheral vascular disease, preoperative intra-aortic balloon pumping, perioperative ventricular arrhythmias, primary indication for surgery, number of diseased vessels, left main stenosis, poorly visualized distal vessels, mitral regurgitation, and use of the LITA. Variables actually included in the Cox analysis were age, sex, symptoms at rest, congestive heart failure, mitral regurgitation, number of diseased vessels, and poorly visualized vessels. Statistical significance of differences in the Kaplan-Meier survival curves were determined by using the log-rank test.

Population characteristics. Population characteristics are shown in Table I. There were 125 patients in both the study and control groups (112 men and 13 women). Average age was $60 \pm 10$ years. The groups were comparable with respect to comorbid factors (including diabetes, hypertension, and peripheral vascular disease), severity of angina, need for preoperative intra-aortic balloon pump support, and extent of coronary artery disease (Table II). 
Table IV. Results

\begin{tabular}{lccc}
\hline & Study group & Control subjects & P value \\
\hline Hospital mortality & $5 / 125(4 \%)$ & $14 / 125(11 \%)$ & .03 \\
Low-output syndrome & $24 / 125(19 \%)$ & $37 / 125(30 \%)$ & .06 \\
Perioperative myocardial & $5 / 125(4 \%)$ & $9 / 125(7 \%)$ & $>.2$ \\
$\quad$ infarction & & & \\
Postoperative IABP & $19 / 125(15 \%)$ & $38 / 125(30 \%)$ & .004 \\
Stroke & $5 / 125(4 \%)$ & $4 / 125(3 \%)$ & $>.2$ \\
Reoperation for bleeding & $1 / 125(1 \%)$ & $2 / 125(2 \%)$ & $>.2$ \\
Sternal wound infection & $3 / 125(2 \%)$ & $4 / 125(3 \%)$ & $>.2$ \\
\hline
\end{tabular}

IABP, Intra-aortic balloon pump.

In the study group the primary indication for the operation was angina in $50 \%$, heart failure in $7 \%$, angina and heart failure in $29 \%$, and ventricular arrhythmia in $2 \%$. In the remaining patients with critical anatomy, an operation was recommended to improve prognosis. Preoperative ventricular arrhythmia was documented in $31 \%$ of patients, $54 \%$ had at least 1 poorly visualized vessel, and $38 \%$ had mild-to-moderate mitral regurgitation (2 to $3+$ ).

The groups were comparable with respect to the degree of systemic hypothermia, the proportion receiving crystalloid or blood cardioplegia, and the proportion receiving antegrade or retrograde (with or without antegrade) cardioplegia. Only 11 patients in the control group received anything other than cold cardioplegia.

Table III lists intraoperative variables. The crossclamp and pump times were longer in the study group. Seventy-five percent of study patients had a LITA graft versus $56 \%$ in the control group $(P=.005)$.

\section{Results}

The operative mortality rate was $4 \%$ in study patients versus $11 \%$ in control subjects $(P=.03$, Table IV $)$. Low-output syndrome occurred in 19\% of study patients and $30 \%$ of control subjects $(P=.06)$. Intraaortic balloon pump support was required in $15 \%$ of study group patients versus $30 \%$ of control subjects $(P$ $=.004)$. The prevalence of perioperative complications, including myocardial infarction, stroke, reoperation for bleeding, and sternal infection, was similar in the two groups.

As determined by using univariate analysis, the hospital mortality rate was not related to the technique of cardioplegia: antegrade versus retrograde (with or without antegrade) cardioplegia 17 (8.4\%) of 202 versus $2(6.5 \%)$ of $31(P>.2)$ or the degree of hypothermia (mild vs moderate) $8(6.7 \%)$ of 120 versus 11 $(9.2 \%)$ of $130(P>.2)$. The hospital mortality rate was, however, significantly lower in patients in whom cardioplegia was guided by temperature mapping (5 [4\%] of 125 vs 14 [11.2\%] of $125, P=.03$ ).

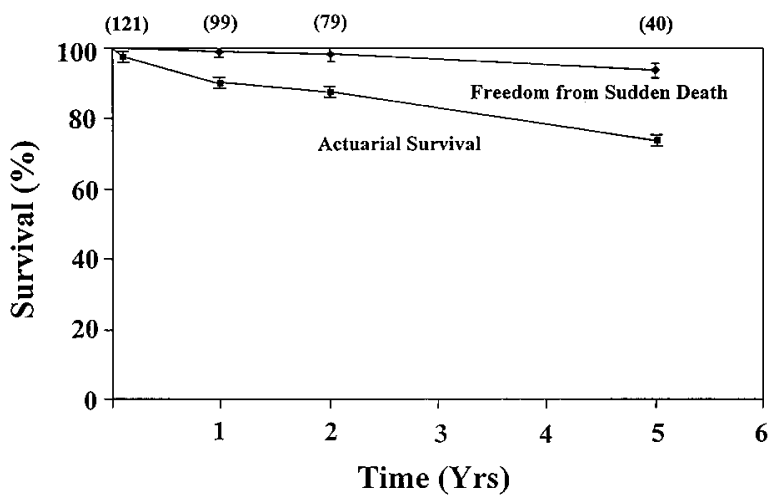

Fig 1. Study group: actuarial survival and freedom from sudden death at 1,2 , and 5 years.

With respect to hospital deaths in the study group, 1 patient receiving long-term amiodarone died of acute respiratory distress syndrome, 1 with a preoperative intra-aortic balloon pump for cardiogenic shock died of congestive heart failure, 1 died of low-output syndrome, and 2 died of ventricular arrhythmias. In this group antiarrhythmic medication (not including $\beta$ blockers) was required briefly ( $<24$ hours) to suppress premature ventricular contractions in 18 (14\%) of 125 patients. Prolonged antiarrhythmic therapy was used in an additional $41(33 \%)$ patients (19 for premature ventricular contractions, 14 for ventricular tachycardia/ ventricular fibrillation [VT/VF], and in 8 patients drugs were given prophylactically because of a history of VT/VF). Twenty-seven (22\%) patients were discharged with antiarrhythmic medications.

In the control group hospital deaths were related to congestive heart failure or low-output syndrome in 8 and ventricular arrhythmia in 2 patients. One patient died of a pulmonary embolus. In 3 patients the cause of death could not be determined (charts destroyed).

Follow-up in study patients extends from 6 months to 15 years (mean, $48 \pm 39$ months). There have been 33 late deaths (4 sudden deaths, 17 nonsudden cardiac deaths, 4 noncardiac deaths, and 8 deaths of unknown cause). At 5 years, actuarial survival is $72 \%$, and freedom from sudden death is $94 \%$ (Fig 1).

By using univariate analysis, 4 preoperative variables adversely affected long-term survival-advanced age, overall class IV symptoms, heart failure class IV symptoms, and poorly visualized distal vessels. A LITA graft favorably affected long-term survival. According to multivariate Cox regression analysis, age, overall class IV symptoms, and poorly visualized vessels predicted decreased long-term survival. Other preoperative variables, such as the presence or absence of significant angi- 

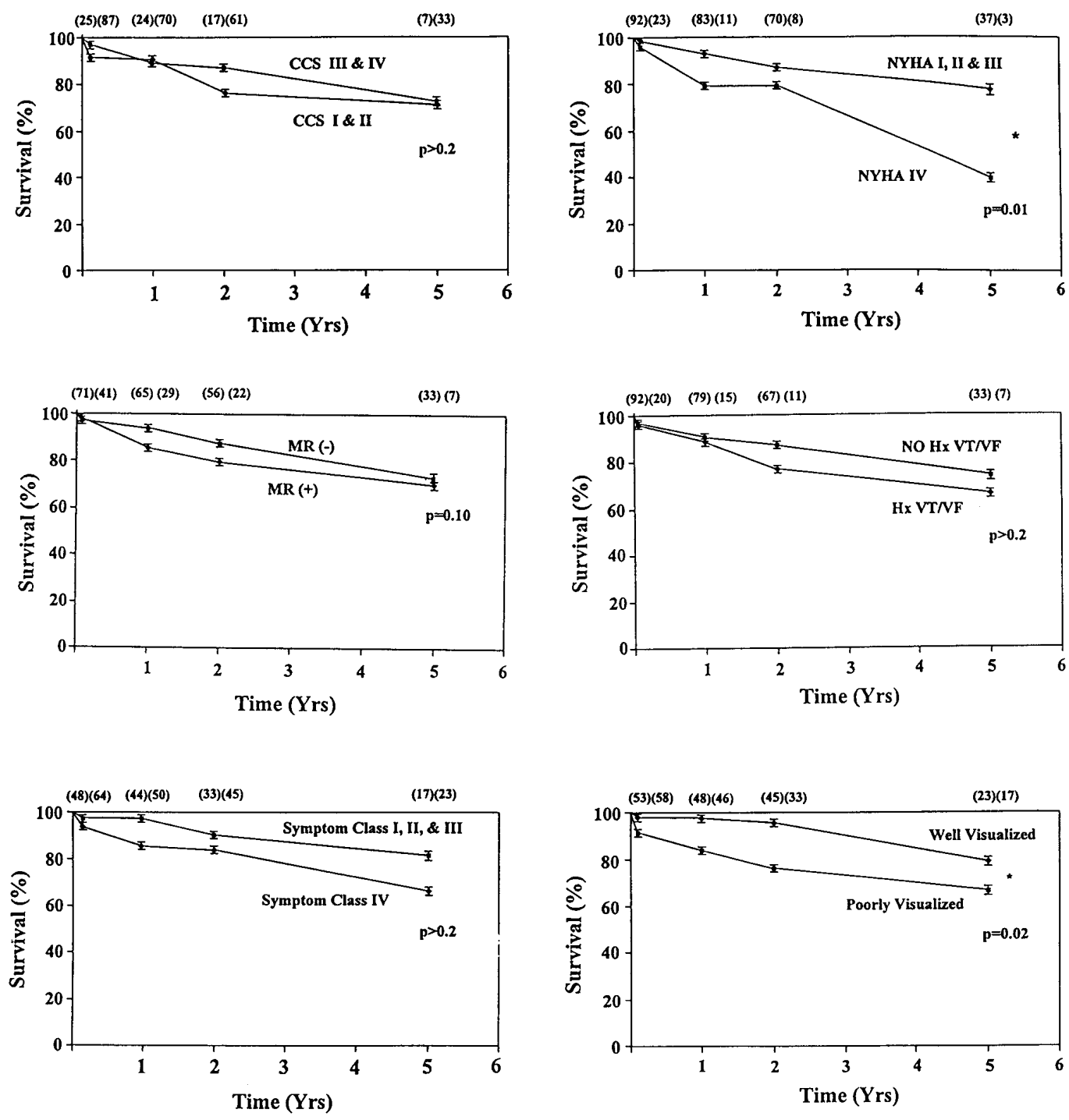

Fig 2. Actuarial survival for patient subgroups with and without significant angina (Canadian Cardiovascular Society [CCS ] class III and IV vs I and II), class IV heart failure symptoms, significant mitral regurgitation, preoperative ventricular arrhythmia, overall class IV symptoms, and poorly visualized distal vessels. Asterisks (*) indicate a statistically significant difference between curves as determined by using the log-rank test $(P<.05)$. NYHA, New York Heart Association; MR, mitral regurgitation.

na, ventricular arrhythmia, or significant mitral regurgitation (2 to $3+$ ), had no effect on long-term survival (Fig 2).

Fig 3 compares preoperative and postoperative symptom status for angina and heart failure among survivors in the study group. Mean anginal class improved from $3.2 \pm 1.0$ preoperatively to $1.3 \pm 0.7$ postoperatively, and $66(74 \%)$ of 89 were improved by at least one Canadian Cardiovascular Society class $(P=.07$ by linear trend analysis). The mean congestive heart failure class improved from $2.2 \pm 1.2$ preoperatively to $1.4 \pm$ 0.7 postoperatively, and $36(40 \%)$ of 89 were improved by at least one New York Heart Association class $(P=$ .04 by linear trend analysis).

During follow-up, 34 (39\%) of 88 of survivors have required rehospitalization, 20 for cardiac reasons (15 for congestive heart failure, including 2 myocardial infarctions, and 5 for arrhythmias, including 2 with atrial fibrillation). No patient has been referred for transplantation, mitral valve replacement, or insertion of an automatic implantable cardioverter defibrillator. A permanent pacemaker was implanted in 2 patients for bradyarrhythmia. 


\section{Discussion}

Medical treatment of patients with coronary disease and poor LV function is associated with poor results. Louie and colleagues ${ }^{4}$ reported a less than 25\% 3-year survival in 54 patients (mean EF, 22\%), and Luciani and colleagues ${ }^{5}$ reported a $28 \%$ 5-year survival in 72 patients (mean EF, 21\%).

Cardiac transplantation is very effective, but the number of transplants is limited by donor availability. ${ }^{17}$ Only $10 \%$ of eligible patients actually undergo transplantation, and many die on the waiting list. ${ }^{18}$

Results of this study support the use of bypass grafting in patients with low EF $(<20 \%)$. Our hospital mortality rate of $4 \%$ and 1 - and 5-year survival of $90 \%$ and $72 \%$ compare favorably with those from recent series in which hospital mortality rates ranged from $2.6 \%$ to $13 \%$ and 5-year survival ranged from $50 \%$ to $73 \% .^{7,10,19,20}$ Clearly, case selection, as well as anesthetic and cardioplegic techniques, may account for these differences.

Case selection. Recent studies have suggested that increased LV size is a risk factor for perioperative mortality in patients with low EF undergoing bypass surgery. ${ }^{21}$ With poor ventricular function and chamber dilatation, it is often impossible, on the basis of preoperative ventriculography, to determine what areas of the heart may benefit from revascularization (hibernating myocardium) and what areas have undergone significant scarring and thinning, in which case partial ventriculectomy and surgical reconstruction may be of benefit. ${ }^{5,15}$ Some centers recommend preoperative viability studies to select patients for revascularization. ${ }^{9,11,13}$ Patients without evidence of flow-metabolism mismatch and without an area of obvious dyskinesis may be considered poor candidates for surgery.

We believe that all patients with graftable coronary disease, poor LV function, and akinetic or dyskinetic regions of the ventricle will benefit from surgery. We recommend intraoperative assessment of regional wall thickness and contractility to guide the operative procedure. If the area in question is scarred, thinned, and nonfunctioning, we proceed with excision to decrease LV volume and wall stress. During the time frame of this study, 53 patients with an EF of less than $20 \%$ have undergone partial ventriculectomy or aneurysm resection. Our results with this approach have been previously reported. ${ }^{15}$ If the akinetic or dyskinetic area corresponds to a thick region of myocardium mixed with scar or if contractility is observed in the unloaded state (on bypass), then revascularization is carried out. Either way, surgery has something to offer. Our operative mortality rate of $4 \%$ and 5-year survival of $72 \%$ com-
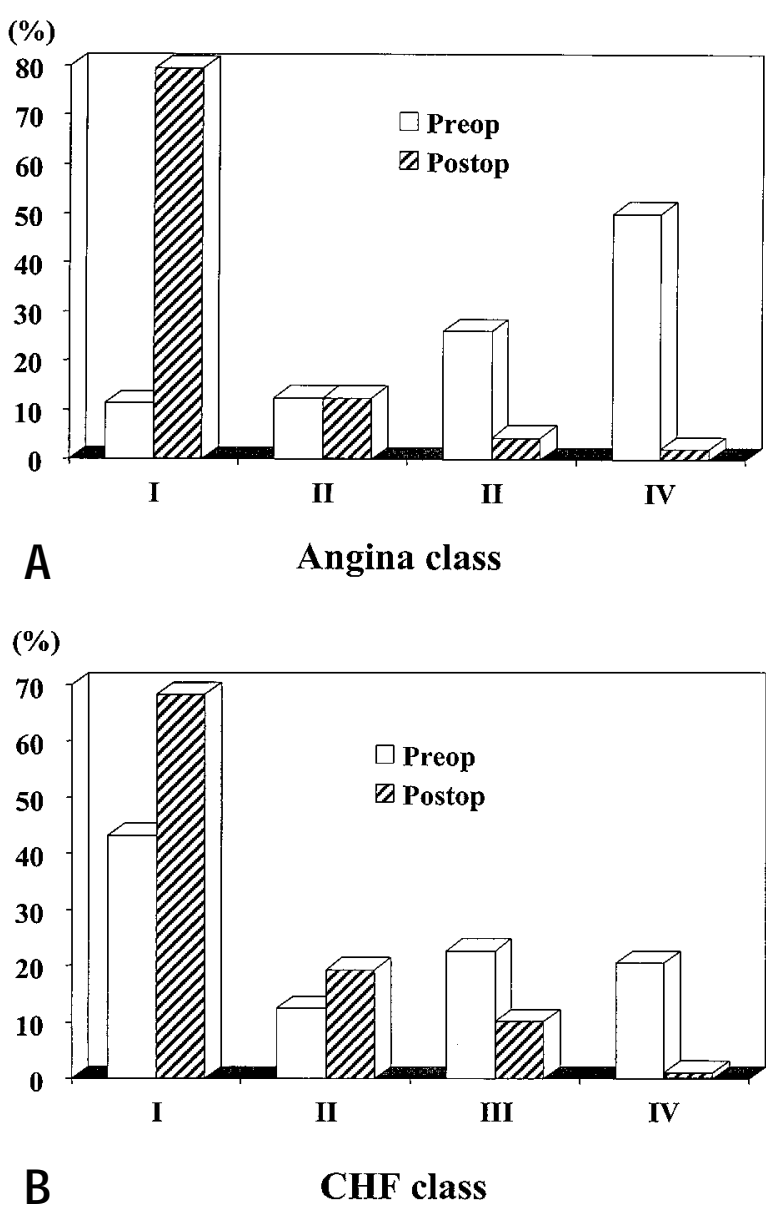

Fig 3. Preoperative (preop) and postoperative (postop) symptom status for angina (Canadian Cardiovascular Society $[C C S]$ ) and congestive heart failure (New York Heart Association [NYHA]) in survivors showing percentage of patients in each group.

pare favorably with results recently reported by DiCarli and colleagues in patients ( $\mathrm{EF}<40 \%)$ who had flowmetabolism mismatch on positron emission tomographic scanning: operative mortality rate of $11 \%^{11}$ and 5-year survival of $75 \% .^{12}$

Langenburg and colleagues ${ }^{14}$ have recommended that patients with poor LV function and poor visualization of distal vessels are not good candidates for revascularization. Our study group included 67 patients with at least one poorly visualized vessel. Poor visualization on the preoperative angiogram does not necessarily correlate with poor quality of distal vessels or incomplete revascularization at surgery. For example, in patients with a poorly visualized left anterior descending artery, 24 of 25 were successfully grafted. In 16 patients with a poorly visualized circumflex, 14 were grafted, with 1 
endarterectomy. In 41 patients with poor visualization of the right coronary artery, 38 were grafted, but 13 endarterectomies were required. Therefore, of 67 patients with poorly visualized vessels, complete revascularization was achieved in all but 6 .

Four of 5 hospital deaths occurred in patients with poorly visualized vessels ( 1 with incomplete revascularization), and the long-term survival rate in this group was significantly lower than that found in patients with well-visualized vessels (Fig 2). Nevertheless, 67\% of patients with poorly visualized vessels were alive at 5 years. For this reason, we will continue to include such patients in our series. We consider inoperable only those with EFs of less than $20 \%$ and poor visualization or evidence of diffuse disease in all three vessel distributions.

Cardioplegic techniques. We agree with Kaul and colleagues $^{20}$ that myocardial protection is extremely important in patients with poor LV function. Any single approach to delivery of cardioplegic solution may result in inadequate protection (antegrade delivery because of coronary stenosis or undetected aortic insufficiency and retrograde delivery because of inadequate flow to the right coronary bed or imperfect coronary sinus catheter position). With cold cardioplegia, temperature mapping can be used to assess delivery, and additional doses can be given retrograde or down initially completed grafts to ensure rapid uniform cooling. ${ }^{22,23}$ We used this technique in our study group.

In control subjects various cardioplegic techniques were used, including tepid or warm cardioplegia in a small subset of 11 patients. In control subjects temperature mapping was not used to ensure uniform cardioplegia delivery.

Improved results in the study group. We attempted to determine what factors were responsible for the lower hospital morbidity and mortality rates observed in the study group (mortality $4 \%$ vs $11 \%, P=.03$; intra-aortic balloon pump support $15 \%$ vs $30 \%, P=$ .004). Unfortunately, the number of hospital deaths in this series is too small to allow meaningful multivariate analysis. By study design, control patients were matched for factors expected to affect morbidity and mortality rates, including LV function, age, sex, overall symptom class, and urgency of surgery. ${ }^{24}$ The two groups were also comparable with respect to comorbidities, extent of coronary disease, and number of grafts performed. Crossclamp time and pump time were longer in study patients in keeping with time needed for temperature mapping and additional cardioplegia delivery.

More study patients received an internal thoracic artery (ITA) graft; however, the hospital mortality rate was not different in patients receiving a LITA (10/161 [6.3\%]) versus those without $(9 / 90[10 \%], P>.2)$. Although it is possible that increased use of the ITA may have contributed to improved results in study patients, we believe that the decreased hospital morbidity and mortality rates in this group were likely caused by improved myocardial protection afforded by temperature mapping.

Ventricular arrhythmia. In previous reports of patients with low EF undergoing revascularization, ventricular arrhythmia has been a common cause of hospital and late death.,10 Kaul and colleagues ${ }^{20}$ reported that long-term survival was decreased in patients with a history of VT/VF. His group did not perform preoperative electrophysiologic studies and used drug therapy or automatic implantable cardioverter defibrillators to control postoperative arrhythmia.

We have had a special interest in the surgical treatment of ventricular arrhythmia, and $25 \%$ of our study group had a history of VT/VF. In our center patients with coronary disease and spontaneous VT/VF have preoperative electrophysiologic testing. If $\mathrm{VT}$ is inducible, they are considered for directed surgical VT ablation and excluded from this series. ${ }^{25}$ Our study group included 10 patients turned down for VT surgery because of age greater than 65 years, noninducible VT, or lack of a transmural scar to allow access for endocardial ablation. All but one of these patients survived the operation and were discharged with antiarrhythmic drugs. In study patients postoperative ventricular arrhythmias were treated with amiodarone as the drug of choice. This aggressive approach (surgical VT ablation when possible or treatment with amiodarone) may explain our results with only 2 hospital deaths caused by arrhythmias (1.6\%) and only 4 late sudden deaths in this series.

Control of symptoms and long-term survival. We and others ${ }^{11,19}$ have demonstrated that improvement in both anginal and heart failure status can be achieved with revascularization in patients with poor ventricular function. In our series, by multivariate analysis, the only predictors of decreased long-term survival were advanced age, overall symptom class IV, and poorly visualized vessels. Other factors identified in previous series as predicting poor outcome, including female sex, hypertension, absence of significant angina, ventricular arrhythmia, or moderate mitral regurgitation, were not related to poor outcome in this series. ${ }^{10,24}$

Our results support the use of coronary artery bypass grafting in patients with poor ventricular function $(\mathrm{EF}<$ $20 \%$ ) and no area suitable for partial ventriculectomy or surgical remodeling. We have shown that good results 
can be achieved without case selection on the basis of viability studies or visibility of distal vessels. We recommend use of temperature mapping to ensure uniform cardioplegia delivery, which may result in decreased operative morbidity and mortality rates. The procedure provides good relief of symptoms in most patients. In our experience the long-term survival was encouraging and was not significantly different in subgroups with or without severe angina, mild-to-moderate mitral regurgitation, or a preoperative history of ventricular arrhythmia. Older patients, those having class IV symptoms, and those with poorly visualized vessels had a poorer long-term prognosis. Although postoperative ventricular arrhythmias were frequent in this group, there were only 2 hospital deaths caused by arrhythmia, only $22 \%$ of patients were discharged with antiarrhythmic drugs, and freedom from sudden death was $94 \%$ at 5 years. Revascularization should be considered as a treatment option whenever possible in patients with coronary artery disease and poor LV function.

\section{REFERENCES}

1. Pigott JD, Kouchoukos NT, Oberman A, Cutter GR. Late results of surgical and medical therapy for patients with coronary artery disease and depressed left ventricular function. J Am Coll Cardiol 1985;5:1036-45.

2. Franciosa JA, Wilen M, Ziesche S, Cohn JN. Survival in men with severe chronic left ventricular failure due to either coronary heart disease or idiopathic dilated cardiomyopathy. Am J Cardiol 1983;51:831-6.

3. The SOLVD Investigators. Effect of enalapril on survival in patients with reduced left ventricular ejection fraction and congestive heart failure. N Engl J Med 1991;325:293-302.

4. Louie HW, Laks H, Milgalter E, et al. Ischemic cardiomyopathy: criteria for coronary revascularization and cardiac transplantation. Circulation 1991;84(Suppl):III290-5.

5. Luciani GB, Faggian G, Razzolini R, Livi U, Bortolotti U, Mazzucco A. Severe ischemic left ventricular failure: coronary operation or heart transplantation? Ann Thorac Surg 1993;55:719-23.

6. Oldham HN Jr, Kong Y, Bartel AG, et al. Risk factors in coronary artery bypass surgery. Arch Surg 1972;105:918-23.

7. Kron IL, Flanagan TL, Blackbourne LH, Schroeder RA, Nolon SP. Coronary revascularization rather than cardiac transplantation for chronic ischemic cardiomypathy. Ann Surg 1989;210: 348-54.

8. Blakeman BM, Pifarré R, Sullivan H, Castanzo-Nordin MR, Zucker MJ. High risk-heart surgery in the heart transplant candidate. J Heart Transplant 1990;9:468-72.

9. Kleikamp G, Posival H, Minami K, El-Banayosy A, Korfer R. Ischemic cardiomyopathy-revascularization vs transplantation. Eur J Cardiothorac Surg 1997;11(Suppl):S1-4.

10. Lansman SL, Cohen M, Galla JD, et al. Coronary bypass with ejection fraction of 0.20 or less using centigrade cardioplegia: long-term follow-up. Ann Thorac Surg 1993;56:480-6.

11. DiCarli MF, Asgarzadie F, Schelbert HR, et al. Quantitative relation between myocardial viability and improvement in heart failure symptoms after revascularization in patients with ischemic cardiomyopathy. Circulation 1995:92;3436-44.

12. DiCarli MF, Maddahi J, Rokhsar S, et al. Long-term survival of patients with coronary artery disease and left ventricular dysfunction: implications for the role of myocardial viability assessment in management decisions. J Thorac Cardiovasc Surg 1999; 116:997-1004

13. Afridi I, Grayburn PA, Panza JA, Oh JK, Zoghbi WA, Marwick TH. Myocardial viability during dobutamine echocardiography predicts survival in patients with coronary artery disease and severe left ventricular systolic dysfunction. J Am Coll Cardiol 1998;32:921-6.

14. Langenburg SE, Buchanan SA, Blackbourne LH, et al. Predicting survival after coronary revascularization for ischemic cardiomyopathy. Ann Thorac Surg 1995;60:1193-7.

15. Mickleborough LL, Maruyama H, Liu P, Mohamed S. Results of left ventricular aneurysmectomy with a tailored scar excision and primary closure technique. J Thorac Cardiovasc Surg 1994;107: 690-8

16. Mickleborough LL, Maruyama H, Takagi Y, et al. Results of revasculatization in patients with severe left ventricular dysfunction. Circulation 1995;92(Suppl):II73-9.

17. Kaye MP. The Registry of the International Society for Heart and Lung Transplantation: Ninth Official Report-1992. J Heart Lung Transplant 1992;11:599-606.

18. Evans RW, Manninen DL, Garrison LP Jr, Maier AM. Donor availability as the primary determinant of the future of heart transplantation. JAMA 1986;255:1892-8.

19. Elefteriades JA, Morales DLS, Gradel C, Tollis C, Levi E, Zaret BL. Results of coronary artery bypass grafting by a single surgeon in patients with left ventricular ejection fraction $\leq 30 \%$. Am J Cardiol 1997;79:1573-8.

20. Kaul TK, Agnihotri AK, Fields BL, et al. Coronary artery bypass grafting in patients with an ejection fraction of twenty percent or less. J Thorac Cardiovasc Surg 1996;111:1001-12.

21. Kawachi K, Kitamura S, Hasegawa T, et al. Increased risk of coronary artery bypass grafting for left ventricular dysfunction with dilated left ventricle. J Cardiovasc Surg 1997;38:501-5.

22. Grondin CM, Helias J, Vouhé PR, Robert P. Influence of a critical coronary artery stenosis on myocardial protection through cold potassium cardioplegia. J Thorac Cardiovasc Surg 1981; 82:608-15.

23. Fishman NH, Abouav J. Myocardial temperature differences as a guide to the order of coronary artery bypass anastomoses in highrisk patients. Am J Surg 1980;140:92-8.

24. Hausmann H, Warnecke H, Schiessler A, et al. Predictors of survival in patients with left ventricular ejection fraction of 10-30\% receiving coronary artery bypass grafting: analysis of preoperative variables in 177 patients. Circulation 1991;84(Suppl):II284-6.

25. Mickleborough LL, Mizuno, Downar E, Gray G. Late results of operation for ventricular tachycardia. Ann Thorac Surg 1992;54: 832-9. 